\title{
Contagem de Staphylococcus sp. e detecção de enterotoxinas estafilocócicas e toxina da síndrome do choque tóxico em amostras de leite cru refrigerado
}

\author{
[Staphylococcus sp. counting and detection of staphylococcal enterotoxins and toxic shock toxin \\ syndrome from cooled raw milk]
}

\author{
H.C. Lamaita ${ }^{1}$, M.M.O.P. Cerqueira ${ }^{2}$, L.S. Carmo $^{3}$, D.A. Santos ${ }^{3}$, C.F.A.M. Penna ${ }^{2}$, M.R. Souza ${ }^{2}$ \\ ${ }^{1}$ Mestrando - EVUFMG - Belo Horizonte \\ ${ }^{2}$ Escola de Veterinária da UFMG \\ Caixa Postal 567 \\ 30123-970 - Belo Horizonte, MG \\ ${ }^{3}$ Fundação Ezequiel Dias - Belo Horizonte
}

\begin{abstract}
RESUMO
Analisaram-se 80 amostras de leite cru refrigerado a $4^{\circ} \mathrm{C}$ e estocado por 48 horas em tanques refrigeradores de propriedades rurais do estado de Minas Gerais quanto à contagem e identificação de Staphylococcus sp. e detecção de enterotoxinas estafilocócicas (SE) e da toxina da síndrome do choque tóxico (TSST-1). Staphylococcus sp. foi detectado em $100 \%$ das amostras de leite de tanque refrigerador em contagens que variaram de $1,0 \times 10^{5}$ a 2,5 $\times 10^{7} \mathrm{UFC} / \mathrm{ml}($ média $=5,60 \log \mathrm{UFC} / \mathrm{ml} ; \mathrm{s}=0,53$ e CV = 9,5\%). Isolaram-se e identificaram-se 436 estirpes como: $S$. aureus, $S$ hyicus, $S$. epidermidis, $S$. intermedius, S. cohnii, S. sciuri, S. schleirferi e S. delphini. As estirpes de mesmo perfil bioquímico, oriundas da mesma amostra, foram agrupadas (pools) e induzidas a produzir SE e TSST-1. A detecção dessas enterotoxinas foi feita pelo método optimum sensitivity plate, usando-se técnica de celofane sobre ágar. Identificou-se a produção de SEA, SEB, SEC, SED e de TSST-1 em percentuais variados. Dos 138 pools preparados, 91 produziram, pelo menos, uma toxina isoladamente ou em associação a outras toxinas. Dos pools enterotoxigênicos, $24,6 \%$ eram coagulase positiva e $41,3 \%$, coagulase negativa. A confirmação de estirpes enterotoxigênicas de Staphylococcus coagulase negativa isoladas de amostras de leite é importante em relação à saúde pública.
\end{abstract}

Palavras-chave: leite cru, Staphylococcus, enterotoxina, TSST-1

\begin{abstract}
In order to count and identify Staphylococcus sp., the detection of the Staphylococcal enterotoxins (SE) and toxic shock toxin syndrome (TSST-1), 80 raw milk samples cooled at $4^{\circ} \mathrm{C}$ and stored in bulk tanks for 48 hours in different farms from Minas Gerais State were analyzed. Staphylococcus sp. was observed in all samples and the counts varied from $1.0 \times 10^{5}$ to $2.5 \times 10^{7} \mathrm{CFU} / \mathrm{ml}$ (mean $=5.60 \mathrm{log} \mathrm{CFU} / \mathrm{ml}$; sd $=$ 0.53 and $C V=9.46 \%$ ). A total of 436 strains of Staphylococcus were isolated and identified as $\mathrm{S}$. aureus, S hyicus, S. epidermidis, S. intermedius, S. cohnii, S. sciuri, S. schleirferi and S. delphini. Strains showing identical biochemical profile, from the same sample, were grouped into a pool and them were induced to produce SE and TSST-1. The detection of toxins was made by the OSP (Optimum Sensivity Plate) method and the cellophane-over-agar technique. It was identified SEA, SEB, SEC, SED and TSST1 in different percentages. From the 138 formed pools, 91 produced, at least, one or more toxin,
\end{abstract}

Recebido para publicação em 25 de agosto de 2004

Recebido para publicação, após modificações, em 15 de fevereiro de 2005

*Autor para correspondência (corresponding author)

E-mail: monicerq@vet.ufmg.br 
including TSST-1. From the enterotoxigenic pools, 24.6\% were coagulase positive, while $41.3 \%$ were negative. The presence of entorotoxigenic negative coagulase Staphylococcus strains isolated from milk samples is important in relation to public health.

Keywords: raw milk, Staphylococcus, enterotoxins, TSST-1

\section{INTRODUÇÃO}

Surtos de intoxicação de origem alimentar são problemas freqüentes em todo o mundo (Bergdoll, 1989). O leite e seus derivados são excelentes meios para o desenvolvimento de microrganismos desejáveis, patogênicos e deteriorantes (Teuber, 1992). Entre o grupo dos patogênicos, destacam-se espécies de Staphylococcus por serem consideradas causas comuns de toxinfecções alimentares (Carmo e Bergdoll, 1990). Os fatores que contribuem para a elevada freqüência desses surtos incluem a baixa qualidade do leite cru, além da sua manipulação indevida desde a fazenda produtora até o comércio varejista (Sena, 2000).

O período de incubação da intoxicação estafilocócica é curto, variando de 15 minutos a 6 horas após a ingestão do alimento contaminado (Carmo, 2001). Os sintomas variam de acordo com a susceptibilidade individual, sendo mais graves em recém-nascidos, idosos e pessoas acometidas de doenças crônicas imunossupressoras (Cliver, 1994). O restabelecimento ocorre geralmente em período de um a dois dias (Bergdoll, 1989).

Enterotoxinas estafilocócicas (SE) são os principais agentes de intoxicação de origem bacteriana no homem e têm sido relatadas em vários surtos de doenças transmissíveis por alimentos. As toxinas são termoestáveis (Cliver, 1994) e originam sintomas como vômito e diarréia, dentre outros (Bergdoll, 1989). É necessário menos de $1 \mu \mathrm{g}$ de toxina pura para desencadear os sintomas característicos de intoxicação estafilocócica, sendo que a população de $10^{5}$ UFC de Saphylococcus/g ou ml de alimento é necessária para provocar um quadro de intoxicação (Bergdoll, 1989).

Os tipos de $\mathrm{SE}$ conhecidos são A e B (Casman et al., 1963); $\mathrm{C}_{1}, \mathrm{C}_{2}, \mathrm{C}_{3}$ (Bergdoll et al., 1965), D (Casman et al., 1967); E (Bergdoll et al., 1971); G (Munson e Betley, 1991); H (Su e Wong, 1995), I (Munson et al., 1998); J (Zhang et al.,
1998); K (Orwin et al., 2001); L e M (Jarraud et al., 2001). Uma mesma cepa de $S$. aureus pode produzir mais de um tipo de enterotoxina (Bergdoll, 1989).

O método de escolha mais comum para enumeração de $S$. aureus na maioria dos produtos lácteos é o da contagem em placas pelo ágar Baird Parker (Standard... 1992). As técnicas de detecção das SE fundamentam-se no uso de anticorpos (Bergdoll et al., 1959), tendo sido o método optimum sensitivity plate (OSP) desenvolvido para permitir a maior sensibilidade possível (Robbins et al., 1974).

Outro fator de virulência descrito na literatura é a toxina da síndrome do choque tóxico (TSST-1) (Cardoso, 1999). Essa toxina é provavelmente susceptível à clivagem pela pepsina, podendo ser menos estável nos intestinos em comparação com SE (Dinges, 2000). A doença causada pela TSST-1 é aguda e caracteriza-se por febre alta, hipotensão e envolvimento de três ou mais órgãos sistêmicos, dentre outros (Chesney, 1989).

Devido à importância de espécies de Staphylococcus, de SE e da TSST-1 no leite utilizado pelas indústrias e pelos laticínios e aos riscos à saúde pública, este trabalho se propôs a realizar a contagem e a identificação das espécies de Staphylococcus bem como a detecção das enterotoxinas e da TSST-1 nas amostras de leite cru refrigerado coletadas em fazendas leiteiras.

\section{MATERIAL E MÉTODOS}

Oitenta amostras de leite cru foram coletadas em diferentes propriedades produtoras de leite localizadas nas proximidades da área metropolitana de Belo Horizonte, no período de outubro a dezembro de 2002. As propriedades foram selecionadas de acordo com o volume diário de produção de leite e classificadas em pequenas, médias e grandes produtoras. Amostras de leite, estocadas em tanques 
refrigeradores por período máximo de 48 horas, foram coletadas em frascos estéreis com capacidade para $210 \mathrm{ml}$, acondicionadas em caixa isotérmica contendo gelo e transportadas sob refrigeração até o laboratório, onde foram submetidas à enumeração de Staphylococcus sp.

Foram preparadas diluições decimais seriadas até $10^{-6} \mathrm{em}$ frascos contendo água peptonada tamponada estéril (Lancette e Tatini, 1992) e, em seguida, alíquotas correspondentes a $100 \mu \mathrm{l}$ de cada diluição foram transferidas para placas de Petri contendo ágar Baird Parker (uma placa por diluição) e incubadas a $35-37^{\circ} \mathrm{C}$ durante 48 horas. As placas que apresentaram colônias típicas e atípicas foram encaminhadas ao laboratório de enterotoxinas estafilocócicas para a identificação das espécies de Staphylococcus e para detecção de SE e da TSST - 1 .

Selecionaram-se, em média, três colônias típicas e três atípicas, a partir das placas que apresentaram contagens entre 25 e 250UFC suspeitas de Staphylococcus e confirmadas pela prova de Gram. O resultado das contagens foi anotado para colônias típicas e atípicas, sendo multiplicado pelo inverso da diluição e por 10, resultando em UFC de Staphylococcus sp. por mililitro de leite (Lachica et al., 1969; Lancette e Tatini, 1992).

As estirpes foram transferidas para tubos de hemólise contendo $1,0 \mathrm{ml}$ de caldo infuso cérebro coração (BHI) e incubadas a $37^{\circ} \mathrm{C}$ por 24 horas. A partir de cada subcultivo, as estirpes foram submetidas às provas de coagulase, termonuclease, fermentação da maltose e do manitol, além de hemólise em ágar sangue de carneiro. A partir dos resultados das provas de fermentação da maltose e do manitol, realizou-se a prova de catalase, segundo metodologias propostas por Mac Faddin (1980) e Kloos (1990).

Para a detecção das SE e da TSST-1, as toxinas utilizadas como padrão e os anti-soros específicos foram gentilmente cedidos pelo doutor Luiz Simeão do Carmo, do laboratório de enterotoxinas estafilocócicas da Fundação Ezequiel Dias.

As estirpes originárias de mesma amostra de leite que apresentaram perfil bioquímico idêntico foram transferidas para um tubo contendo $5 \mathrm{ml}$ de caldo infuso cérebro coração (BHI) e incubadas a $37^{\circ} \mathrm{C}$ por 24 horas, compreendendo um pool das culturas. Dessa forma, prepararam-se 138 pools, que foram testados para a produção de enterotoxinas estafílocócicas e de TSST-1 pelo método OSP, segundo Robbins et al. (1974). Os resultados foram, então, submetidos à análise de estatística descritiva.

\section{RESULTADOS E DISCUSSÃO}

O crescimento de colônias semelhantes a Staphylococcus em ágar Baird Parker, após incubação a $37^{\circ} \mathrm{C}$ por 48 horas, foi observado em $100 \%$ das amostras de leite cru (Tab. 1). A contagem média de Staphylococcus variou de 1,0 $\times 10^{5}$ a $2,5 \times 10^{7} \mathrm{UFC} / \mathrm{ml}$, média igual a $3,99 \times$ $10^{5} \mathrm{UFC} / \mathrm{ml}(5,60 \log \mathrm{UFC} / \mathrm{ml}) ; \mathrm{s}=0,53$ e $\mathrm{CV}=$ $9,5 \%$. Isso pode ser explicado pela diversificação de sistemas de produção e de manejos utilizados pelos produtores, o que leva à maior ou menor contaminação do leite por Staphylococcus sp. devido à mastite e/ou por contaminação de retireiros portadores assintomáticos.

Tabela 1. Freqüência de Staphylococcus sp. (UFC/ml) em leite in natura estocado em tanques refrigeradores de 80 propriedades de Minas Gerais

\begin{tabular}{lcc}
\hline Staphylococcus sp. $(\mathrm{UFC} / \mathrm{ml})$ & \multicolumn{2}{c}{$\begin{array}{c}\text { Freqüência de } \\
\text { isolamento }\end{array}$} \\
\hline & $\mathrm{n} / \mathrm{N}$ & $\%$ \\
$1,0 \times 10^{5}$ a $1,0 \times 10^{6}$ & $64 / 80$ & 80,0 \\
$1,1 \times 10^{6}$ a $1,0 \times 10^{7}$ & $15 / 80$ & 18,75 \\
$>1,1 \times 10^{7}$ & $1 / 80$ & 1,25 \\
\hline
\end{tabular}

Os níveis de contaminação das amostras de leite cru por espécies de Staphylococcus foram superiores aos descritos na literatura. No Brasil, segundo Bergdoll (1990ab), a contagem média em leite in natura desse microrganismo é de $10^{5}$ $\mathrm{UFC} / \mathrm{ml}$, constituindo riscos de produção de SE. Cerqueira et al. (1994) e Carmo et al. (1995) verificaram alta contaminação de leite e derivados por S. aureus. Gomes e Gallo (1995) observaram contagens de $1,2 \times 10^{3}$ a 7,4 $\times 10^{5}$ $\mathrm{UFC} / \mathrm{mL}$ de Staphylococcus sp. em amostras de leite cru comercializado em Piracicaba, SP.

As contagens de Staphylococcus sp. observadas por Carmo et al. (2002) em amostras de leite cru 
foram inferiores às obtidas de queijos fabricados com o leite analisado. Esses alimentos foram a causa provável de toxinfecção alimentar em uma cidade do estado de Minas Gerais. Segundo Chaffer et al. (1999), em 96 quartos de glândulas mamárias de 24 novilhas em Israel, 67 não apresentaram crescimento bacteriano $(69,8 \%), 29$ estavam contaminadas por Staphylococcus coagulase negativa $(27,1 \%)$ e três contaminadas por $S$. aureus $(3,1 \%)$.

Verificou-se que Staphylococcus aureus foi a espécie mais freqüentemente isolada (Fig. 1).

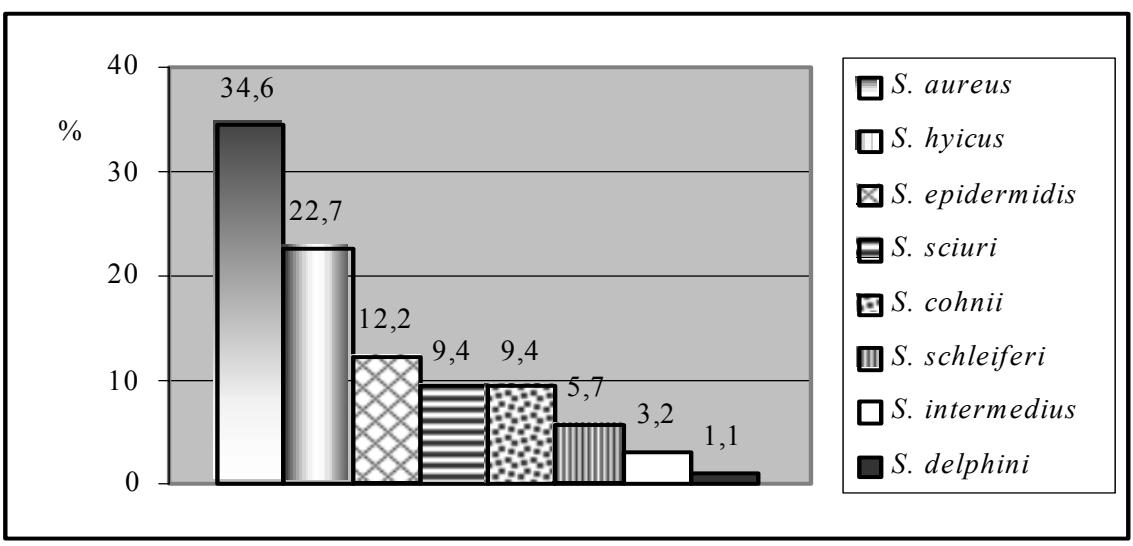

Figura 1. Freqüência (\%) das espécies de Staphylococcus isoladas de amostras de leite cru estocado em tanques refrigeradores de 80 propriedades de Minas Gerais.

Os resultados deste estudo foram similares aos descritos por Sena (2000), que, ao analisar 637 cepas de Staphylococcus sp. isoladas de queijos tipo coalho, identificou que 218 eram de $S$. aureus (58,0\%); 96 de Staphylococcus coagulase negativa $(25,0 \%) ; 41$ de $S$. hyicus $(11,0 \%)$ e 22 de $S$. intermedius $(6,0 \%)$. Desse modo, o leite utilizado para a fabricação de queijos muitas vezes já se apresenta contaminado, mesmo antes do início do processamento. Isto sinaliza para a adoção urgente de um programa nacional de melhoria da qualidade do leite, que inclua, entre outros parâmetros, Staphylococcus sp.

Dos 138 pools de Staphylococcus testados quanto ao potencial para a produção de enterotoxinas e de TSST-1 pelo método OSP, 46 foram caracterizados como $S$. aureus (33,3\%); 23 como $S$. epidermidis $(16,7 \%) ; 19$ como $S$. sciuri (13,8\%); 17 como $S$. cohnii (12,3\%); 14 como $S$. hyicus $(10,1 \%) ; 10$ como $S$. schleiferi $(7,2 \%) ; 7$ como $S$. intermedius $(5,1 \%)$ e 2 como $S$. delphini $(1,5 \%)$. Neste estudo, foram detectadas as enterotoxinas A, B, C e D e a toxina TSST-1 produzidas pelas linhagens de Staphylococcus sp. isoladas nas amostras de leite de tanques refrigeradores.

A produção de SE e de TSST-1 pelas cepas de Staphylococcus sp. isoladas foi variável, sendo detectadas isoladamente ou em associação (Tab. 2). Percebe-se que as cepas isoladas das amostras de leite cru são altamente toxigênicas $(65,9 \%)$. Estes resultados assemelham-se aos obtidos por Cardoso (1999), que observou valores de 65,4\% de toxigenicidade nas amostras isoladas, também de leite cru.

Genigeorgis (1989) e Bergdoll (1989) revisaram trabalhos identificando Staphylococcus aureus, além de outras espécies do gênero como enterotoxigênicas, contradizendo afirmações de que somente espécies coagulase positiva são enterotoxigênicas e de que espécies coagulase negativa são sempre não enterotoxigênicas, não constituindo, portanto, riscos à saúde. De acordo com Bennett (1996), a positividade para a enzima coagulase tem sido usada para indicar patogenicidade de um isolado toxigênico e a presença da enzima termonuclease, sugerida como indicador mais confiável dessa 
enterogenicidade. Segundo Bergdoll (1989), se uma cepa apresenta resultados positivos para a produção das enzimas coagulase e termonuclease, pode ser considerada como potencialmente produtora de enterotoxinas. No presente estudo, o percentual de cepas enterotoxigênicas positivas para os testes de coagulase e termonuclease é apresentado nas Fig. 2 e 3 .

Tabela 2. Distribuição da produção de enterotoxinas estafilocócicas (SE) e de toxina da síndrome do choque tóxico (TSST-1), tomadas isoladamente e em associação, pelas cepas isoladas de amostras de leite cru estocado em tanques refrigeradores de 80 fazendas do estado de Minas Gerais

\begin{tabular}{lcc}
\hline Toxina & $\begin{array}{c}\text { Número } \\
\text { de pools }\end{array}$ & $\%$ \\
\hline SEA & 5 & 3,5 \\
SEB & 13 & 9,3 \\
SEC & 20 & 14,4 \\
SED & 6 & 4,2 \\
TSST-1 & 1 & 0,7 \\
SEB + SEC & 13 & 9,4 \\
SEB + SED + TSST-1 & 3 & 2,2 \\
SEB + SEC + TSST-1 & 3 & 2,2 \\
SEA + SEB + SEC & 1 & 0,7 \\
SEA + SEB & 2 & 1,4 \\
SEA + SEB + SED & 2 & 1,4 \\
SEA + SEB + SEC + SED & 3 & 2,2 \\
SEB + SED & 4 & 2,8 \\
SEA + TSST-1 & 1 & 0,7 \\
SEB + SEC + SED & 2 & 1,4 \\
SEA + SEC +TSST-1 & 1 & 0,7 \\
SEA + SED & 2 & 1,4 \\
SEC + TSST-1 & 1 & 0,7 \\
SEB + TSST-1 & 1 & 0,7 \\
SEC + SED & 3 & 2,2 \\
SEA + SEC & 1 & 0,7 \\
Nenhuma & 47 & 34,1 \\
Todas & 3 & 2,2 \\
Total & 138 & 100,0 \\
\hline
\end{tabular}

Considerando o elevado percentual de linhagens de Staphylococcus enterotoxigênicos e negativos para o teste de coagulase, é necessária a revisão da legislação brasileira, uma vez que não existem padrões que considerem esses microrganismos como também importantes do ponto de vista de segurança alimentar. O que se tem disponível são padrões legais especificando somente a presença de espécies coagulase positiva. Tal fato é de extrema importância em termos da saúde pública, uma vez que existem trabalhos disponíveis na literatura (Cardoso, 1999; Sena, 2000; Carmo, 2001; Pimentel et al., 2002) comprovando a toxigenicidade das espécies coagulase negativa, o que pode, mais uma vez, ser confirmado pelos resultados deste trabalho. Constatou-se que $24,6 \%$ dos pools que apresentaram resultado positivo para a prova da coagulase produziram algum tipo de toxina, contra 41,3\% dos pools enterotoxigênicos, coagulase negativa (Fig. 2). Esses resultados indicam que, no caso de leite cru, espécies não produtoras de coagulase produziram enterotoxinas em maior freqüência.

É importante a consideração desses resultados pelos órgãos oficiais de inspeção e de vigilância sanitária no sentido de rever a atual legislação vigente no país em relação ao Staphylococcus sp., pois os tratamentos térmicos disponíveis para o leite não são capazes de inativar as enterotoxinas nele presentes, constituindo risco potencial para o consumidor. Sugere-se, então, a determinação de padrões para Staphylococcus sp., e não somente para Staphylococcus coagulase positiva como é hoje preconizado. Melhor seria, ainda, preconizar a identificação de enterotoxinas nos diferentes alimentos, para garantir a real segurança dos mesmos.

\section{CONCLUSÕES}

Alta contaminação por espécies de Staphylococcus produtores de SE e de TSST-1 em leite cru coletado de tanques refrigeradores pode ser uma das causas que explica a elevada freqüência de contaminação de derivados do leite, justificando os surtos de intoxicação estafilocócica. Os dados sugerem elevado número de animais com mastite e, ainda, provável percentual de retireiros portadores assintomáticos dessa bactéria e ineficiente refrigeração do leite imediatamente após a ordenha. 


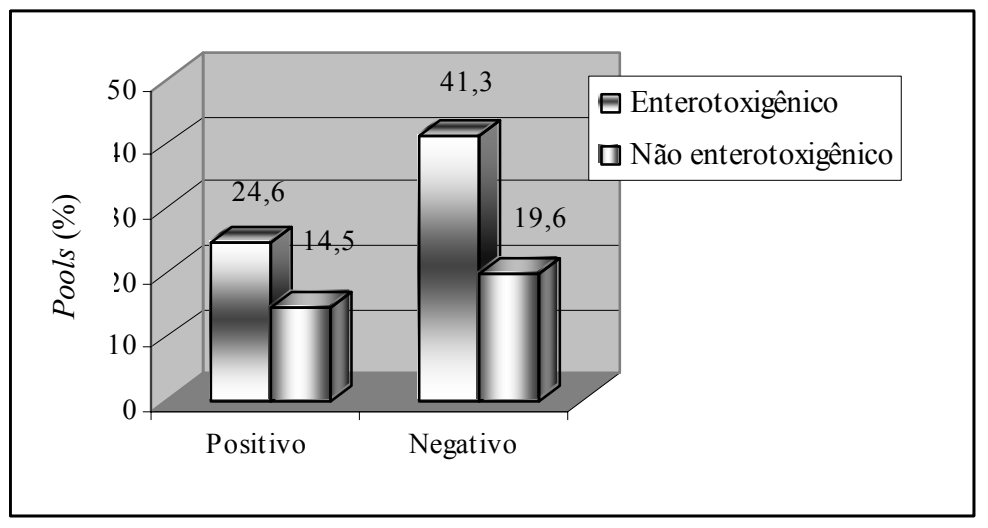

Figura 2. Percentagem de pools de Staphylococcus sp. enterotoxigênicos e não enterotoxigênicos que apresentaram resultado positivo ou negativo no teste da coagulase.

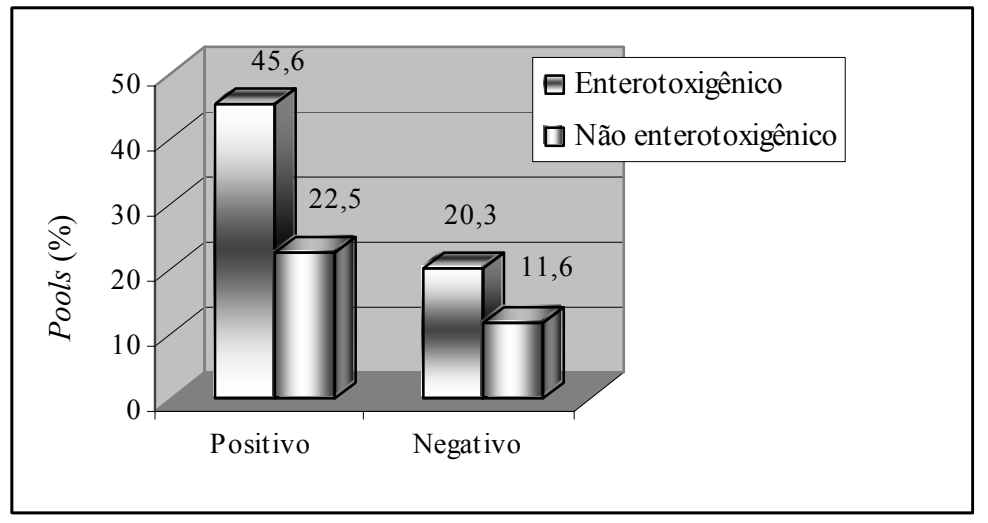

Figura 3. Porcentagem de pools enterotoxigênicos de Staphylococcus sp. e não enterotoxigênicos que apresentaram resultado positivo ou negativo no teste da termonuclease.

\section{REFERÊNCIAS BIBLIOGRÁFICAS}

BENNETT, R.W. Atypical Toxigenic Staphylococcus and Non-Staphylococcus aureus Species on the Horizon? An update. J. Food Protec., v.59, p.1123-1126, 1996.

BERGDOLL, M.S. Analytical methods for Staphylococcus aureus. Int. J. Food Microbiol., v.10, p.91-100, 1990a.

BERGDOLL, M.S. Staphylococcal food poisoning. In: CLIVER, D.O. (Ed.). Foodborne diseases. London: Academic, 1990b. p.87-106.

BERGDOLL, M.S. Staphylococcus aureus. In: Foodborne bacterial pathogens. New York: Marcel Dekker, 1989. p.463-523.
BERGDOLL, M.S.; BORJA, C.R.; AVENA, R.M. Identification of a new enterotoxin as enterotoxin C. J. Bacteriol., v.90, p.1481-1485, 1965.

BERGDOLL, M.S.; BORJA, C.R.; ROBBINS, R.N. Identification of Enterotoxin E. Inf. Immunol., v.4, p.593-595, 1971.

BERGDOLL, M.S.; SURGALLA, M.J.; DACK, G.M. Staphylococcal enterotoxin. identification of a specific precipitating antibody with enterotoxin-neutralizing property. J. Immunol., v.83, p.334-338, 1959.

CARDOSO, F.H.T. Identificação de fatores de virulência e susceptibilidade a antimicrobianos de Staphylococcus aureus isolados de amostras 
de leite bovino em Minas Gerais. 1999. 88f. Dissertação (Mestrado em Medicina Veterinária Preventiva) - Escola de Veterinária, Universidade Federal de Minas Gerais, Belo Horizonte.

CARMO, L.S. Produção e purificação em grande escala das enterotoxinas estafilocócicas $S E A, S E B, S E C_{2}, S E D$ e TSST-1 para uso em ensaios imuno-enzimáticos. 2001. 254f. Tese (Doutorado em Microbiologia) - Instituto de Ciências Biológicas, Universidade Federal de Minas Gerais, Belo Horizonte.

CARMO, L.S.; BERGDOLL, M.S. Staphylococcal food poisoning in Belo Horizonte (Brazil). Rev. Microbiol., v.21, p.320-323, 1990.

CARMO, L.S.; DIAS, R.S.; ANUNCIAÇÃO, L.L.C. et al. Staphylococcal food poisoning in Minas Gerais State, Brazil. Arq. Bras. Med. Vet. Zootec., v.47, p.113-122, 1995.

CARMO, L.S.; DIAS, R.S.; LINARDI, V.R. et al. Food poisoning due to enterotoxigenic strains of Staphylococcus present in Minas cheese and raw milk in Brazil. Food Microbiol., v.19, p.914, 2002.

CASMAN, E.P.; BERGDOLL, M.S.; ROBINSON, J. Designation of staphylococcal enterotoxin. J. Bacteriol., v.85, p.715-716, 1963.

CASMAN, E.P.; BENNET, A.E.; ISSA, J.A. et al. Identification of a fourth staphylococcal enterotoxin, enterotoxin D. J. Bacteriol., v.94, p.1875-1882, 1967.

CERQUEIRA, M.M.O.P.; SOUZA, M.R.; RODRIGUES, R. et al. Características microbiológicas de leite cru e beneficiado em Belo Horizonte (MG). Arq. Bras. Med. Vet. Zootec., v.46, p.713-721, 1994.

CHAFFER, M.; LEITNER, G.; WINKLER, M. et al. Coagulase-negative Staphylococci and mammary gland infectious in cows. J. Vet. Med. $B$, v.46, p.707-712, 1999.

CHESNEY, P.J. Clinical aspects and spectrum of illness of toxic shock syndrome: overview. Rev. Inf. Dis., v.11, p.51-57, 1989.

CLIVER, D.O. Foodborne disease handbook: diseases caused by bacteria. New York: Marcel Dekker, 1994. 613p.

DINGES, M.M.; ORWIN, P.M.; SCHLIEVERT, M.P. Exotoxins os produtos elaborados por
Staphylococcus aureus. Clin. Microbiol. Rev., v.13, p.16-34, 2000.

GENIGEORGIS, C. Present state of knowledge on staphylococcal intoxication. Int. J. Food Microbiol., v.9, p.327-360, 1989.

GOMES, H.A.; GALLO, C.R. Ocorrência de Staphylococcus aureus e produção de enterotoxinas por linhagens isoladas a partir de leite cru, leite pasteurizado tipo $\mathrm{C}$ e queijo "Minas Frescal" comercializados em Piracicaba SP. Ciên. Tecnol. Alim. v.15, p.158-161, 1995.

JARRAUD, S.; PEYTRAT, M.A.; LIM, A. et al. A Highly prevalence operon of enterotoxin gene, forms a putative nursery of superantigens in Staphylococcus aureus. J. Immunol., v.166, p.669-677, 2001.

KLOOS, W.E. Systematics and the natural history of staphylococci. J. Appl. Bacteriol., v.70, p.25-37, 1990.

LACHICA, R.V.F.; WEISS, K.F.; DEIBEL, R.H. Relationships among coagulase, enterotoxin and heat stable deoxyribonuclease production by Staphylococcus aureus. Appl. Microbiol., v.18, p.126-127, 1969.

LANCETTE, G.A.; TATINI, S.R. Staphylococcus aureus. In: VANDERZANT, C.; SPLITTSTOESSER, D.F. Compendium of methods for the microbiological examination of foods. 3.ed. Washington: APHA, 1992. p.533547.

MAC FADDIN, J.F. Pruebas bioquímicas para la identificación de bacterias de Importancia Clinica. Buenos Aires: Panamericana, 1980. 301p.

MUNSON, S.H.; BETLEY, M.J. Partial characterization of a new staphylococcal enterotoxin gene. In: GENERAL MEETING OF THE AMERICAN SOCIETY FOR MICROBIOLOGY, 91. Washington, 1991. v.6, p.31.

MUNSON, S.H.; TERMAINE, M.T.; BETLEY, M.J. et al. Identification and Characterization of Staphylococcal Enterotoxin Types G and I from Staphylococcus aureus. Inf. Immun., v.66, p.3337-3348, 1998.

ORWIN, P.M.; LEUNG, D.Y.M.; DONAHUE, H.L. et al. Biochemical and Biological Properties of Staphylococcal Enterotoxin K. Inf. Immun., v.69, p.360-366, 2001. 
PIMENTEL, F.E.; DIAS, R.S.; CARMO, L.S. et al. Presença de Staphylococcus sp enterotoxigênico e de enterotoxinas em queijo ralado. Rev. Inst. Lat. Cândido Tostes, v.57, p.227-229, 2002.

ROBBINS, R.; GOULD, S.; BERGDOLL, M.S. Detecting the enterotoxigenicity of Staphylococcus aureus Strains. Appl. Microbiol., v.28, p.946-950, 1974.

SENA, M.J. Perfil epidemiológico, resistência a antibióticos e aos conservantes nisina e sistema lactoperoxidase de Staphylococcus sp isolados de queijos coalho comercializados em Recife $P E$. 2000. 75f. Tese (Doutorado em Ciência Animal) - Escola de Veterinária, Universidade Federal de Minas Gerais, Belo Horizonte.
STANDARD methods for the examination of dairy products: american public health association. 16.ed. Washington, DC: Robert T. Marshall, 1992. 546p.

SU, Y-C.; WONG, A.C.L. Identification and Purification of a New Staphylococcal Enterotoxin, H. Appl. Environ. Microbiol., v.61, p.1438-1443, 1995.

TEUBER, M. Microbiologycal problems facing the dairy industry. Bull. Int. Dairy Fed., n.276, p.6-9, 1992.

ZHANG, S.; IANDOLO, J.J. STEWART, C. The enterotoxin C plasmid of Staphylococcus aureus encodes a second enterotoxin determinant (SEJ). FEMS Microbiol. Lett., v.168, p.227-233, 1998. 